\section{PC-042 A SCIENCE- AND RISK-BASED STRATEGY TO QUALIFY STERILISED PREFILLED SYRINGES AS PRIMARY PACKAGING MATERIAL IN A HOSPITAL PHARMACY}

${ }^{1} \mathrm{~K}$ Beld*, ${ }^{1} \mathrm{~A}$ Kuiper, ${ }^{1} \mathrm{~S}$ Van Berkel, ${ }^{1} \mathrm{H}$ Robben, ${ }^{1} \mathrm{R}$ Wijnsma, ${ }^{2} \mathrm{~K}$ Taxis, ${ }^{3} \mathrm{E}$ Frijlink. ${ }^{1}$ ISALA Hospital, Clinical Pharmacy, Zwolle, The Netherlands; ${ }^{2}$ University of Groningen, Unit of Pharmacotherapy- -Epidemiology and Pharmacoeconomics PTE2- Groningen Research Institute of Pharmacy, Groningen, The Netherlands; ${ }^{3}$ University of Groningen, Department of Pharmaceutical Technology and Biopharmacy, Groningen, The Netherlands

10.1136/ejhpharm-2019-eahpconf.123

Background To improve medication safety in hospitals, The Joint Commission International standard recommend implementation of ready-to-administer (RTA) drugs. Many hospital pharmacies facilitate this in aseptic filling of polypropylene single-use syringes. The main disadvantages of this product, though the container is not meant for storage, are the aseptic process, the short shelf-life and the refrigerator capacity. The solution was found in a cyclic olefin polymer (COP) syringe, which can be terminally sterilised. All individual components of the syringe comply with the regulatory demands but to ensure that the new product does not adversely affect patient safety or product quality qualification is required.

Purpose A science- and risk-based strategy to qualify COP syringes as primary packaging material for the production of terminally sterilised RTA syringes with a high speed (semi-) automatic filling and closing machine in a hospital pharmacy.

Material and methods A $50 \mathrm{ml}$ COP syringe with a polypropylene/butyl rubber tip cap and a butyl rubber stopper and a $5 \mathrm{ml}$ COP syringe with an elastomer tip cap and a butyl rubber stopper were used for qualification. Validation batches of $\mathrm{NaCl} 0.9 \%$ with phosphate buffer $\mathrm{pH} 2,5.8,8$ and $11, \mathrm{NaCl}$ $0.9 \%$, isopropyl alcohol (IPA) $5 \%$ in water and water for injections were produced. On $\mathrm{t}=0,1,2,3,4,5,6,9,12,18$ and 24 months the following tests were performed on the batches; clarity and degree of opalescence of the solution $(\mathrm{Ph}$. Eur. 2.2.1.), degree of colouration of the solution (Ph. Eur. 2.2.2), $\mathrm{pH}$ of the solution, absorbance (Ph. Eur 3.2.2.1), reducing substances (Ph. Eur. 3.2.2.1), transparency (Ph. Eur 3.2.2.1), weight loss, subvisible particles (Ph. Eur. 2.9.19), silicon, closure integrity and sterility (Ph. Eur. 2.6.1).

Results All performed tests complied with acceptance criteria according to the Ph. Eur. Monographs. High $\mathrm{pH}$ value (11.8) showed higher absorbance, indicating more extractables and leachables; maximum 0.06 at $\mathrm{t}=24$ months) than neutral $\mathrm{pH}$ ranges (5-8); and maximum 0.02 .

Conclusion The syringes are suitable as primary packaging material for producing RTA products in a hospital pharmacy.

\section{REFERENCES AND/OR ACKNOWLEDGEMENTS}

No conflict of interest.

\section{PC-043 NEW FORMULATION OF NOREPINEPHRINE SOLUTION IN PREFILLED CYCLIC OLEFIN STERILISED SYRINGES}

${ }^{1} \mathrm{~K}$ Beld*, 'S Van Berkel, ${ }^{1} \mathrm{R}$ Wijnsma, ${ }^{2} \mathrm{~K}$ Taxis, ${ }^{3} \mathrm{E}$ Frijlink. 'ISALA Hospital, Clinical Pharmacy, Zwolle, The Netherlands; ${ }^{2}$ University of Groningen, Unit of Pharmacotherapy- Epidemiology and Pharmacoeconomics Pte2- Groningen Research Institute Of Pharmac, Groningen, The Netherlands; ${ }^{3}$ University of Groningen, Department of Pharmaceutical Technology and Biopharmacy, Groningen, The Netherlands

10.1136/ejhpharm-2019-eahpconf.124
Background Norepinephrine is a potent $\alpha$-sympathomimetic drug which plays an important role in the acute treatment of hypotension and shock in an intensive care unit. Commercially available norepinephrine solutions contain sodium metabisulfite $\left(\mathrm{Na}_{2} \mathrm{~S}_{2} \mathrm{O}_{5}\right)$ as an antioxidant. However, the cyclic olefin polymer syringe used in our hospital is not compatible with sodium metabisulfite due to brown colourisation of the syringe during sterilisation.

Purpose To develop a new formulation of $0.1 \mathrm{mg} / \mathrm{ml}$ norepinephrine solution without sodium metabisulfite which is chemically stable and sterile.

Material and methods Pre-formulation tests were performed with $0.1 \mathrm{mg} / \mathrm{ml}$ norepinephrine solution with $0,0.05 \%$ and $0.1 \%$ ascorbic acid added as an antioxidant. Other excipients were $0.1 \mathrm{mg} / \mathrm{ml}$ edetate sodium, $8 \mathrm{mg} / \mathrm{ml}$ sodium chloride and water for injections. The syringes were filled under nitrogen gassing, stored at room temperature and protected from daylight. Concentration of norepinephrine was measured at day $0,8,21$ and 51, and 3 and 5 months with an UHPLC system with diode array detection. Based on the pre-formulation test results, the final formulation was defined and stability testing was performed measuring concentration of norepinephrine, $\mathrm{pH}$, clarity, colour of solution, subvisible particles and sterility at time intervals according to ICH guidelines.

Results The norepinephrine concentration in the pre-formulation tests were $98.4 \%, 96.4 \%$ and $96.4 \%$ at $\mathrm{t}=5$ months for, respectively, no ascorbic acid added, and $0.10 \%$ and $0.05 \%$ ascorbic acid added. Validation batches were produced with norepinephrine, edetate sodium, sodium chloride and water for injections filled under nitrogen gassing. Preliminary results show a concentration of $108.8 \%$ and $109.0 \%$ norepinephrine (10\% more norepinephrine was added due to possible degradation during sterilisation based on historical data) at $t=3$ months.

Conclusion Norepinephrine $(0.1 \mathrm{mg} / \mathrm{ml})$ solution without sodium metabisulfite in a sterilised syringe stored at room temperature protected from daylight, is stable for at least 3 months.

\section{REFERENCE AND/OR ACKNOWLEDGEMENTS}

Larmené-Beld K, Kuiper A, van Berkel S, et al. A scienceand risk-based strategy to qualify sterilised prefilled syringes as primary packaging material in a hospital pharmacy. Abstract submitted for 24th EAHP Congress 2019.

No conflict of interest.

\section{PC-044 PARAFFIN OIL-BASED EMULSION: INFLUENCE OF GUM ARABIC AND THE MIXING RATE ON EMULSION STABILITY}

M Benabbes*, M Alami Chentoufi, L Abdelkader. Faculty of Medicine and PharmacyMohammed V University of Rabat, Team of Formulation and Quality Control of Health Products- Faculty of Medicine and Pharmacy, Rabat, Morocco

\subsection{6/ejhpharm-2019-eahpconf.125}

Background Emulsions form the basis of a wide range of manufactured products in the pharmaceutical domain. They are constituted by at least two non-miscible liquids. However, instability is the major inconvenience of these galenic forms.

Purpose Paraffin oil and gum arabic are used in the formulation of the oil-in-water emulsion type, which has a lot of applications in drug delivery, either as a medicament or as a vehicle. In the hospital pharmacy, the emulsion for intravenous 
administration, for example, must be the oil-in-water type. However, a good stability is required. The aim of the present study is the formulation of emulsion based on paraffin oil and to evaluate the influence of gum arabic content and mixing rate on the stability of emulsions.

Material and methods Distilled water was used as a dispersant phase $(75 \%)$ and paraffin oil as a dispersed phase (20\%). Tween 80 and Span 80 served as mix surfactants (60/40). The formulation was performed according to the Lipophilic Balance-Hydrophilic (HLB) method. Gum arabic concentrations ranging from $2.5 \%-10 \% \mathrm{w} / \mathrm{w}$ were used. The stability of the emulsions was evaluated by centrifugation at $4000 \mathrm{rpm}$ for 15 min. The creamer index (IC) was used for the interpretation of the results. The emulsions thus prepared are mixed at 4000, 8000 and $16000 \mathrm{rpm}$ for $10 \mathrm{~min}$.

Results The IC of emulsions ranged from 29\%-30\% with a HLB of 10.72. High levels of gum arabic (10, 7.5 and 5\% $(\mathrm{w} / \mathrm{w}))$ increased the creaming, therefore the stability was decreased. After addition of $2.5 \%(\mathrm{w} / \mathrm{w})$ of gum arabic, $1.6 \%$ creaming was observed. In $3 \%(\mathrm{w} / \mathrm{w})$ gum arabic-containing emulsion, no creaming was observed. Microscopic images of emulsions mixed at 4000, 8000 and $16000 \mathrm{rpm}$, showed that emulsion prepared at $16000 \mathrm{rpm}$ had homogeneously distributed individual small droplets with no sign of flocculation compared to the others.

Conclusion The present experiment has shown that a concentration of $3 \% \mathrm{w} / \mathrm{w}$ gum arabic, and a mixing rate of $16000 \mathrm{rpm}$ provided the optimum stability of oil-paraffin emulsion.

\section{REFERENCE AND/OR ACKNOWLEDGEMENTS}

Ramin L, et al. Soy protein isolate and gum arabic composite affects stability of beverage emulsion. Iran J Chem Eng $2009 ; 6$.

No conflict of interest.

\section{PC-045 FORMULATION AND STABILITY STUDY OF EXTEMPORANEOUS ORAL LIQUID DOSAGE FORMS CONTAINING FLECAINIDE ACETATE 2 MG/ML FOR PAEDIATRIC USE}

A Casiraghi*, S Loiacono, S Bordignon, R Puzziferri, F Cilurzo, P Minghetti. University of Milan, Department of Pharmaceutical Sciences- Specialisation School in Pharmacy, Milan, Italy

\subsection{6/ejhpharm-2019-eahpconf.126}

Background Flecainide acetate (FlecAc) is an antiarrhythmic drug, effective in children and fetal tachyarrhythmias. FlecAc is commercially available as $50 \mathrm{mg}-150 \mathrm{mg}$ oral tablets or intravenous injectable solutions, approved only for use in adults. For paediatric use, an extemporaneous preparation has to be compounded, using the pure active principle or, when this is lacking, the ground tablet. Few examples of extemporaneous FlecAc preparations are reported in the literature, normally at a dose of $20 \mathrm{mg} / \mathrm{mL}$. Nevertheless, in the case of neonates and infants, a lower concentration is useful.

Purpose The aim of this work was to compound FlecAc oral liquids $(2 \mathrm{mg} / \mathrm{mL})$ using pure powder (API) or ground commercial tablets (GCT) and to evaluate the chemical stability of the active principle.

Material and methods Oral solutions were compounded using either a preserved simple syrup (PSS) with the addition of a suspending phase or a ready-to-use commercial suspending vehicle, ORA-Plus ORA-Sweet (OPOS), to be stored at $4^{\circ} \mathrm{C}$ or $25^{\circ} \mathrm{C}$, respectively. Four types of aqueous solutions were compounded following hospital standard operating procedures. In three different pharmacies, seven hospital pharmacists compounded a total of 28 preparations $(n=28)$ : 1) PSS-API, 2) PSS-GCT, 3) OPOS-API and 4) OPOS-GCT. The samples were stored at $4^{\circ} \mathrm{C}$ (PSS), $25^{\circ} \mathrm{C}$ (OPOS) and $40^{\circ} \mathrm{C}$ (both) for 42 days. The FlecAc content was determined using a stability indicating the high-performance liquid chromatography method.

Results At time $\mathrm{t}=0$, the mean FlecAc content of all samples was $1.82 \pm 0.10 \mathrm{mg} / \mathrm{mL}$, against a labelled content of $2.00 \mathrm{mg} /$ $\mathrm{mL}$. A significant difference in FlecAc content was observed only in the case of GCT preparations (OPOS-GCT: 1.87 $\pm 0.07 \mathrm{mg} / \mathrm{mL}$; PSS-GCT: $1.79 \pm 0.15 \mathrm{mg} / \mathrm{mL}, \mathrm{p}=0.03)$. Based on these results, duration and method of stirring were further investigated and improved in a second batch, which showed a higher mean content and reduced variability $(1.92 \pm 0.06 \mathrm{mg} /$ $\mathrm{mL})$. FlecAc was stable over the entire period.

Conclusion FlecAc is completely solubilised in the proposed vehicles and stable for 42 days. A suspending agent is therefore necessary only to mask the excipients of the tablet, if not completely solubilised. Normally suggested storage in a refrigerator when PSS is compounded should be carefully considered, because of the influence of the reduced temperature on FlecAc solubility.

\section{REFERENCES AND/OR ACKNOWLEDGEMENTS}

No conflict of interest.

\section{PC-046 STUDY OF STABILITY OF TWO LIQUID FORMULATIONS OF OMEPRAZOLE ELABORATED IN THE PHARMACEUTICAL SERVICE}

E Conesa Nicolás*, AM Chica Marchal, AC Viney, S Nuñez Bracamonte, C Juez Santamaría, A Lloret Llorca, B Fernández-Lobato, CN García Matillas, M Martinez Penella. Hospital General Universitario Santa Lucía, Servicio de Farmacia, Cartagena- Murcia, Spain

\subsection{6/ejhpharm-2019-eahpconf.127}

Background As many medicines are not available for paedriatic use they have to be elaborated in the pharmacy service. Generally, there are different formulations described in the bibliography.

Purpose To compare two liquid formulations of omeprazole elaborated in the pharmacy service of a tertiary hospital evaluating physicochemical stability and organoleptic characteristics (OC) with the aim of defining the most ideal formulation.

Material and methods A bibliographic check of the different formulations of omeprazole was carried out and two liquid magistral preparations were elaborated in triplicate. Formulation 1 was prepared from omeprazole monohydrate salt, using as excipients: simple syrup, mixture conservans and purified water. Formulation 2 was prepared from omeprazole capsules using bicarbonate $1 \mathrm{M}$ as excipient. Conditions of refrigeration and of light protection were established. As an indicator of physicochemical stability, the $\mathrm{pH}$ was selected. For its determination a $\mathrm{pH}$ measurer, Mettler Toledo SevenMulti was used. The data was analysed using an Excel 2010 spreadsheet. The results were expressed as average $\pm \mathrm{SD}$. Also colour, smell and taste (OC) were evaluated, as well as homogeneity of the formulations. Thirty days was established as a period of study. The determinations were carried out on days $0,10,17,24$ and 30 post-elaboration. 